\title{
Purification of Chlamydia trachomatis Lymphogranuloma Venereum Elementary Bodies and their Interaction with HeLa Cells
}

\author{
By SUBIR K. BOSE* AND ROBERT G. PAUL \\ Department of Microbiology, St Louis University School of Medicine, St Louis, \\ Missouri 63104, U.S.A.
}

(Received 24 June 1981; revised 23 September 1981)

\begin{abstract}
A procedure has been developed to yield infectious elementary bodies of the lymphogranuloma venereum strains LGV 434 and 404 of Chlamydia trachomatis, labelled during intracellular growth in HeLa 229 cells. The final preparation, obtained after velocity sedimentation of a polycarbonate membrane-filtered sample through a sucrose gradient, is free of host proteins and, more importantly, of chlamydial reticulate bodies. Using such purified preparations, it was found that the association of LGV 434 elementary bodies with HeLa 229 cultures was unaffected by the pretreatment of the host cells with a variety of lectins or with neuraminidases from Clostridium perfringens and Vibrio cholerae. The association was inhibited by dextran sulphate and by mild trypsin treatment of HeLa cultures. Treatment of purified elementary bodies with trypsin, chymotrypsin, neuraminidases and a variety of carbohydrates and lectins did not produce any change in the rate of association with HeLa cultures. Heat-inactivated elementary bodies were significantly less able to associate with the host cells.
\end{abstract}

\section{INTRODUCTION}

The genus Chlamydia consists of obligately parasitic bacteria possessing a complex growth cycle in susceptible animal cells. The infectious coccoid form, the elementary body (EB), attaches to the host membrane, is rapidly internalized and converted within the phagosomal vacuole to the replicating form, the reticulate body (RB). The EB of Chlamydia psittaci 6BC and of lymphogranuloma venereum (LGV) strain 440L of Chlamydia trachomatis associates avidly with such 'non-professional phagocytes' as mouse L and human HeLa cells (Byrne, 1978; Byrne \& Moulder, 1978). To study this 'parasite-specified' interaction (Byrne \& Moulder, 1978) we needed preparations of EBs free of contaminating host material and RBs. We found that over $99 \%$ of infectious EBs of two $C$. trachomatis LGV strains $\left(\mathrm{L}_{2} / 434 / \mathrm{Bu}\right.$ and $\mathrm{L}_{3} / 404 / \mathrm{LN}$ ) grown in monolayer cultures of HeLa 229 remained intracellular, so that not enough extracellular material was available for purification. Previous methods of purification, based on sedimentation through Renografin (3,5-diacetamido-2,4,6triiodobenzoic acid) gradients have yielded infectious preparations with little contaminating host material (Byrne, 1978; Byrne \& Moulder, 1978; Friis, 1972; Kuo \& Grayston, 1976; Lee, 1981; Levy, 1979). However, as also noted by Howard et al. (1974), we found by electron microscopy that samples purified by isopycnic sedimentation through Renografin gradients consisted of both RBs and EBs of LGV 434 and 404. Despite the reported differential sensitivity to ultrasonic vibration and to trypsin of the RBs and EBs of the meningopneumonitis strain of $C$. psittaci (Tamura \& Higashi, 1967), we were unable to obtain infectious samples of pure EBs of $C$. trachomatis strains using published procedures.

\footnotetext{
Abbreviations: EB, elementary body; RB, reticulate body; LGV, lymphogranuloma venereum; EBSS, Earle's balanced salt solution; PBS, phosphate-buffered saline; DPCC, diphenylcarbamoyl chloride.
} 
In this paper we report a rapid technique which yields pure EBs of C. trachomatis LGV strains 434 and 404, with 5-25\% recovery of infectious material, and provide microscopic evidence for homogeneity. Using such EB preparations we have studied various aspects of HeLa cell-LGV interaction. The $L_{2}$ and $L_{3}$ serotypes of LGV strains differ from the $L_{1}$ serotype and C. psittaci 6BC (Byrne \& Moulder, 1978; Levy, 1979) and from the non-LGV trachoma G17 strain (Lee, 1981).

\section{METHODS}

Cell culture. HeLa 229 cells were grown as described by Bose \& Liebhaber (1979), except that the cells were adapted to grow in $5 \%(\mathrm{v} / \mathrm{v})$ calf serum instead of foetal calf serum. The cultures were periodically tested for mycoplasma contamination by radioactive labelling of cultures and sedimentation analysis of the extracellular medium (Wise et al., 1978) and by staining with Hoechst 33258 stain (Chen, 1977) and were found to be mycoplasma-free.

Preparation of chlamydial stock. $\mathrm{LGV} \mathrm{L}_{2} / 434 / \mathrm{Bu}$, a gift from Dr C.-C. Kuo, and $\mathrm{L}_{3} / 404 / \mathrm{LN}$, purchased from American Type Culture Collection, were grown in HeLa 229 monolayer cultures. Approximately $25 \times 10^{6}$ cells were plated in glass Pfizer bottles $\left(690 \mathrm{~cm}^{2}\right)$ containing $300 \mathrm{ml}$ growth medium. After incubation at $37^{\circ} \mathrm{C}$ for $40-48 \mathrm{~h}$ the almost confluent monolayers were infected with about $5 \times 10^{7}$ inclusion-forming units (i.f.u.) of chlamydial inoculum consisting of infected HeLa cells homogenized by eight to ten rapid passages through a 26-gauge needle (Bose \& Liebhaber, 1979). Following adsorption at $37^{\circ} \mathrm{C}$ for $1-2 \mathrm{~h}$, with frequent redistribution of the inoculum by rocking, growth medium containing $1.0 \mu \mathrm{g}$ cycloheximide $\mathrm{ml}^{-1}$ was added to ensure an abundant supply of amino acids for chlamydial development by suppressing host cell protein synthesis. More than $95 \%$ of the cells contained characteristic cytoplasmic inclusions $24-36 \mathrm{~h}$ after infection. The cells were harvested 38-40 h after infection by shaking with sterile glass beads $(2-3 \mathrm{~mm}$ diameter $)$ in $10 \mathrm{ml}$ Earle's balanced salt solution (EBSS) containing $10 \%(\mathrm{v} / \mathrm{v})$ calf serum per bottle. This medium was found to be superior to the phosphate/sucrose medium commonly used to store chlamydiae. Portions $(250 \mu \mathrm{l})$ of infected cells were stored at $-70^{\circ} \mathrm{C}$. The titre ranged from $10^{9}$ to $10^{10}$ i.f.u. $\mathrm{ml}^{-1}$ when harvested. After thawing, a 10 -fold lower titre was obtained.

Titration of infectivity. The technique of Furness et al. (1960) was modified for greater convenience and economy. Portions $(50 \mu \mathrm{l})$ of suspension containing $2-3 \times 10^{4} \mathrm{HeLa} 229$ cells were deposited on the $8 \mathrm{~mm}$ spots of 'printed microslides' (Carlson Scientific, Peotone, Ill., U.S.A.) which had been sterilized by ultraviolet radiation. After incubation at $37^{\circ} \mathrm{C}$ for $18 \mathrm{~h}$, cells in each spot were infected with $20 \mu \mathrm{l}$ of infectious material diluted with EBSS plus $5 \%(\mathrm{v} / \mathrm{v})$ calf serum. Adsorption at $37^{\circ} \mathrm{C}$ was for $1 \mathrm{~h}$. The slides were immersed in growth medium containing $1.0 \mu \mathrm{g}$ cycloheximide $\mathrm{ml}^{-1}$. We found that little horizontal transmission of LGV 434 or 404 took place in $40 \mathrm{~h}$. The medium was removed, cells were fixed in methanol, rinsed once with methanol, and air-dried before staining with Giemsa (Fisher Scientific; diluted 1:12 in 6.67 mM-phosphate buffer, pH 7.4). Cells containing inclusions were counted in multiple fields using a projection microscope and the titre in each inoculum was computed.

Preparation of labelled elementary bodies. Confluent cultures of HeLa 229 were obtained by plating 18-20 $\times$ $10^{6}$ cells in $30 \mathrm{ml}$ growth medium per Falcon $175 \mathrm{~cm}^{2}$ flask. After overnight incubation at $37{ }^{\circ} \mathrm{C}$, the medium was aspirated, and the monolayer was infected with $6 \mathrm{ml}$ of chlamydial inoculum in EBSS plus $5 \%$ calf serum, at an input multiplicity of 10 i.f.u. per cell. Adsorption was allowed for $2 \mathrm{~h}$ at $37^{\circ} \mathrm{C}$ with continuous rocking. Then, the inoculum was aspirated and the infected cells were incubated in $30 \mathrm{ml}$ growth medium containing $1.0 \mu \mathrm{g}$ cycloheximide $\mathrm{ml}^{-1}$. At $20 \mathrm{~h}$ post-infection, the medium was replaced with $20 \mathrm{ml}$ labelling medium which contained only $5 \%$ of the normal amount of methionine (for labelling with $\left[{ }^{35} S\right]$ methionine) or of amino acids (for labelling with ${ }^{3} \mathrm{H}$ - or ${ }^{14} \mathrm{C}$-labelled amino acid mixture), $1 \%(\mathrm{v} / \mathrm{v})$ calf serum and $1.0 \mu \mathrm{g}$ cycloheximide $\mathrm{ml}^{-1}$. For labelling with ${ }^{32} \mathrm{P}$, medium containing $10 \%$ of the normal phosphate concentration was used. After allowing $1 \mathrm{~h}$ for depletion of endogenous pools, $500 \mu \mathrm{Ci}(18.5 \mathrm{MBq})$ of $\left[{ }^{35}\right.$ S]methionine (Amersham; 1050 or $1200 \mathrm{Ci} \mathrm{mmol}^{-1}$ ) or $1 \mathrm{mCi}(37 \mathrm{MBq})$ of ${ }^{3} \mathrm{H}$-labelled amino acids mixture or $50 \mu \mathrm{Ci}(1.85 \mathrm{MBq})$ of ${ }^{14} \mathrm{C}$-labelled amino acids mixture (Amersham) per flask was added.

We found that the cells whose cytoplasmic space was filled with chlamydial inclusions at $46 \mathrm{~h}$ post-infection were especially fragile to manipulations. After removal of growth medium, the monolayer was gently washed with phosphate-buffered saline (PBS) containing $1 \mathrm{~mm}$-EDTA, and $0.7 \mathrm{ml}$ of a solution of crystalline trypsin (Sigma; $1 \mu \mathrm{g} \mathrm{ml}^{-1}$ in PBS/EDTA) was added. After $5 \mathrm{~min}$ at $37^{\circ} \mathrm{C}$, the detached cells were transferred to a sterile $8 \mathrm{ml}$ conical-bottomed polypropylene tube (Kew Scientific, Columbus, Ohio, U.S.A.), and the flask was rinsed with $0.7 \mathrm{ml}$ of $14 \%(\mathrm{w} / \mathrm{v})$ sucrose in EBSS. The pooled cell suspension, kept at $0{ }^{\circ} \mathrm{C}$, was homogenized using a Tekmar SDT emulsifier-type homogenizer equipped with an SDT 100EN shaft and generator (Tekmar Co., Cincinnati, Ohio, U.S.A.), operated at $30 \%$ of the maximum speed to avoid foaming. More than $90 \%$ of the cells were 
disrupted in 5-6 min, yielding 0.9-1.5 $\times 10^{9}$ i.f.u. per flask. These operations were performed in a biohazard hood. The homogenate was centrifuged at $200 \mathrm{~g}$ for $5 \mathrm{~min}$ at $4{ }^{\circ} \mathrm{C}$. The supernatant was removed, and the pellet, which contained $30-40 \%$ of infectivity, was suspended in $0.5 \mathrm{ml}$ of $7 \%(\mathrm{w} / \mathrm{v})$ sucrose in EBSS and recentrifuged. The resulting supernatant was pooled with the first supernatant and filtered through a $25 \mathrm{~mm}$ diameter polycarbonate membrane filter (Nuclepore Corp., Pleasanton, Calif., U.S.A.; $400 \mathrm{~nm}$ pore size) and a glass fibre prefilter. The filtrate (about $1.4 \mathrm{ml}$ ) was layered over a pre-cooled $37 \mathrm{ml}$ linear gradient of $10-40 \%(\mathrm{w} / \mathrm{v})$ sucrose in PBS, and centrifuged at $6000 \mathrm{rev} . \mathrm{min}^{-1}$ for $1 \mathrm{~h}$ in a Beckman SW27 swing-out rotor. Fractions of $1.5 \mathrm{ml}$ were collected from the top using a Buchler Auto Densi-flow Fractionator (Buchler Instruments, Fort Lee, N.J., U.S.A.). Densities were calculated from refractive indices. Samples $(100 \mu l)$ were spotted on $1 \times 1$ in squares of Whatman 3MM paper and processed (Bollum, 1966) before measuring trichloroacetic acid-insoluble radioactivity of the filter paper squares by liquid scintillation spectrometry.

Assessment of the association of labelled EBS with HeLa monolayer cultures. Confluent cultures used were in 24-well Linbro (Carlson Scientific) or 4-well Nunc (Gibco, Grand Island, N.Y., U.S.A.) culture dishes, with a growth surface of $2 \mathrm{~cm}^{2}$. A pair of wells without cells was included in each experiment to measure the binding of labelled EBs to the plastic surface and this 'background' was subtracted from the data from experimental cultures. The final volume of the reaction mixture was $100-200 \mu \mathrm{l}$ per well and appropriate non-radioactive compounds (methionine, amino acids, etc.) were present in the reaction mixture to minimize any possible uptake of radioactivity from unstable incorporated material released from the EBs. The infected cultures were incubated with continuous rocking in a humidified $\mathrm{CO}_{2}$ incubator at $37^{\circ} \mathrm{C}$ for the specified period. The reactions were terminated by aspiration of the inoculum and washing five to ten times with $1 \mathrm{ml}$ PBS per well before resuspending the cells with associated labelled EBs in $300 \mu \mathrm{l}$ PBS containing $1 \mathrm{mM}$-EDTA to obtain a uniform cell suspension. The number of HeLa cells in each well was determined by counting a $100 \mu \mathrm{l}$ sample in a Celloscope particle counter (Particle Data, Elmhurst, Ill., U.S.A.). The cell-associated, labelled EBs were counted by adding a $100 \mu \mathrm{l}$ sample to $0.9 \mathrm{ml}$ of Triton X-100/toluene/Omnifluor (New England Nuclear) scintillation fluid and determining the radioactivity.

Modifications of HeLa cells. Monolayer cultures of HeLa 229 cells were treated with DEAE-dextran, dextran sulphate, crystalline diphenylcarbamoyl chloride (DPCC)-treated trypsin, Clostridium perfringens or Vibrio cholerae neuraminidase, wheat germ agglutinin, concanavalin A, lectins from Dolichos biflorus, Glvcine max or Tetragonolobus purpureas or $\mathrm{N}$-acetylneuraminic acid. Conditions of treatment and concentrations used are described in the legend to Table 2.

Modifications of the labelled purified EBs. Heat-inactivation of the inclusion-forming ability was accomplished by incubation of chlamydiae for $30 \mathrm{~min}$ at $56^{\circ} \mathrm{C}$ or $3 \mathrm{~min}$ at $60^{\circ} \mathrm{C}$. The conditions of treatment with neuraminidase, trypsin, chymotrypsin, DEAE-dextran, sialic acid, fetuin, D-mannose, methyl-D-mannoside, D-mannitol, D-fructose, $N$-acetyl-D-glucosamine, $N$-acetyl-D-galactosamine and D-galactosamine are described in the Results.

Electron microscopy of EBs in the gradient fractions. Samples from the fractions were centrifuged at 13000 rev. $\min ^{-1}$ for $30 \mathrm{~min}$ in a Sorvall HB-4 swing-out rotor to deposit chlamydiae on to Formvar-coated copper grids in Delrin adapters (Friis, 1972). The grids were stained with $1 \%(\mathrm{w} / \mathrm{v})$ uranyl acetate in $7 \%(\mathrm{w} / \mathrm{v})$ sucrose. Electron micrographs were taken with a Philips 300 microscope.

Reagents. Sugar, lectins, chymotrypsin, crystalline DPCC-treated trypsin, chymotrypsin and Clostridium perfringens neuraminidase type $\mathrm{X}$ (unit defined as liberating $1 \mu \mathrm{mol} N$-acetylneuraminic acid per min from $N$-acetylneuramin-lactose) were purchased from Sigma. Vibrio cholerae neuraminidase (unit defined as liberating $1 \mu \mathrm{g} \mathrm{N}$-acetylneuraminic acid per $15 \mathrm{~min}$ from human $\alpha_{1}$-acid glycoprotein) was from Gibco. DEAE-dextran (mol. wt $2 \times 10^{6}$ ) and dextran sulphate were from Pharmacia.

\section{RESULTS}

Several suspending media such as PBS containing $7 \%(\mathrm{w} / \mathrm{v})$ sucrose, minimal essential medium alone or with 5 or $10 \%(\mathrm{v} / \mathrm{v})$ calf or foetal calf serum, EBSS plus 5 or $10 \%(\mathrm{v} / \mathrm{v})$ serum, and EBSS plus $7 \%(\mathrm{w} / \mathrm{v})$ sucrose were tested to determine the medium optimal for maintaining infectivity of $C$. trachomatis LGV 434 and 404 . EBSS plus $5 \%$ calf serum and EBSS plus $7 \%$ sucrose were found to be the best.

There was approximately $50 \%$ loss of infectivity when EBs of C. trachomatis LGV 434 were sedimented so this procedure was avoided. Repeated experiments showed that, as noted before (Howard et al., 1974), RBs and EBs of LGV 434 co-sedimented to equilibrium in a variety of Renografin gradients (Fig. 1). Velocity sedimentation achieved partial separations, although the infectious fractions were always contaminated with RBs. Since the latter are 


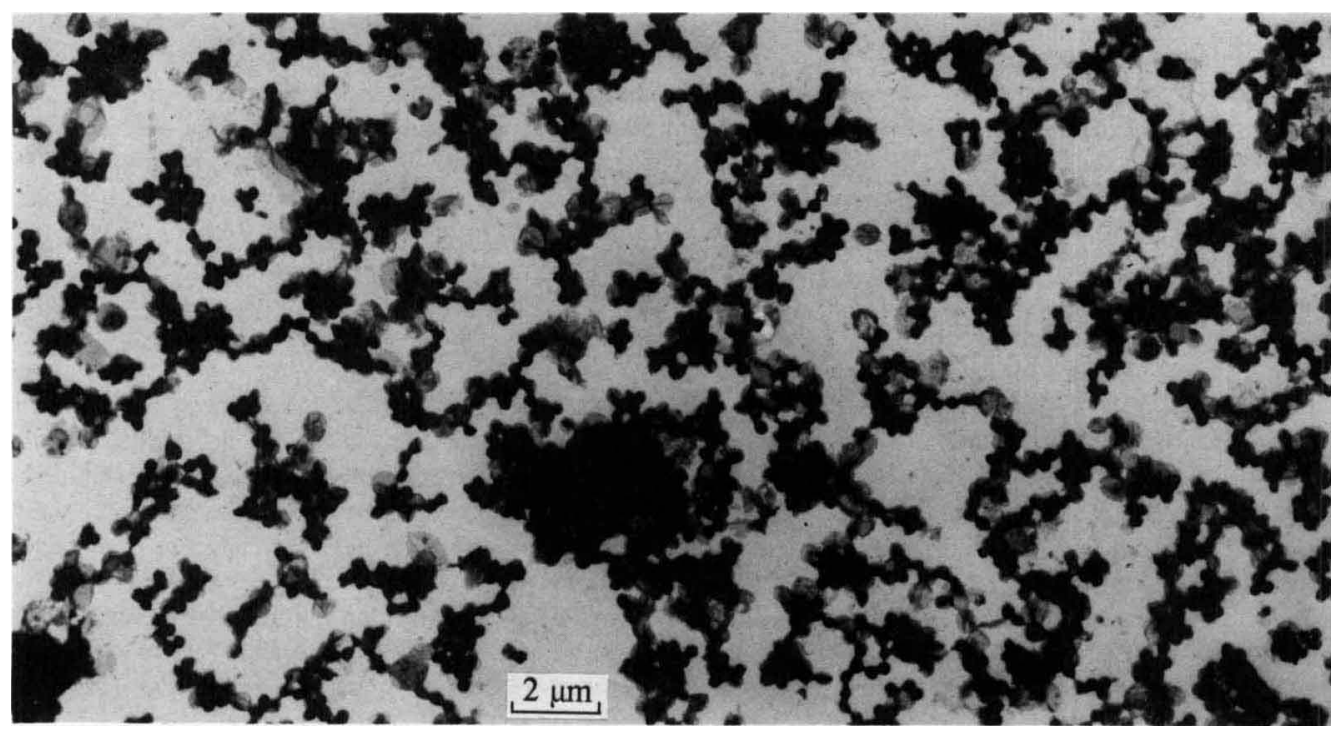

Fig. 1. Electron micrograph of infectious $C$. trachomatis LGV 434 purified by isopycnic sedimentation in a $20-40 \%(\mathrm{v} / \mathrm{v})$ Renografin gradient at $72000 \mathrm{~g}$ for $45 \mathrm{~min}$ at $5^{\circ} \mathrm{C}$ in a Spinco SW27 swing-out rotor. Electron-dense coccoid particles with an average diameter of $300 \mathrm{~nm}$ are the elementary bodies. Larger particles are the developmental forms, the intermediate and reticulate bodies which are less electron dense.

\section{Table 1. Purification of elementary bodies of C. trachomatis LGV 434}

HeLa cells were plated in Falcon $175 \mathrm{~cm}^{2}$ flasks. Approximately $24 \mathrm{~h}$ later, the monolayer cultures (about $2 \times 10^{7}$ cells) were infected at a multiplicity of 10 i.f.u. per cell. In experiment 1 , at $21 \mathrm{~h}$ postinfection, the growth medium containing cycloheximide was replaced by labelling medium containing $5 \%$ of the normal amount of methionine, $1 \%$ calf serum and $0.7 \mu \mathrm{g}$ cycloheximide $\mathrm{ml}^{-1}$. After a further $1 \mathrm{~h}, 25 \mu \mathrm{Ci}\left[{ }^{35} \mathrm{~S}\right]$ methionine $\mathrm{ml}^{-1}$ was added and the infected cells were incubated until $44.5 \mathrm{~h}$. Labelling medium was then removed, and growth medium containing cycloheximide was added. Cells were harvested $1 \mathrm{~h}$ later and processed (see Methods). In experiment 2, infected cells were incubated until harvested in growth medium containing $1 \mu \mathrm{g}$ cycloheximide $\mathrm{ml}^{-1}$.

\begin{tabular}{|c|c|c|c|c|c|c|}
\hline \multirow[b]{2}{*}{ Expt no. } & \multirow[b]{2}{*}{ Sample } & \multicolumn{2}{|c|}{ Infectivity } & \multicolumn{2}{|c|}{ Radioactivity } & \multirow{2}{*}{$\begin{array}{c}\text { Specific } \\
\text { activity } \\
\text { (c.p.m. per i.f.u. }\end{array}$} \\
\hline & & $\begin{array}{c}\text { Total } \\
\left(10^{-8} \times \text { i.f.u. }\right)\end{array}$ & $\begin{array}{l}\text { Recovery } \\
(\%)\end{array}$ & $\begin{array}{c}\text { Total } \\
\left(10^{-8} \times \text { c.p.m. }\right)\end{array}$ & $\begin{array}{l}\text { Recovery } \\
\text { (\%) }\end{array}$ & \\
\hline 1 & $\begin{array}{l}\text { Homogenate, }{ }^{35} \mathrm{~S} \text {-labelled } \\
200 \mathrm{~g} \text { supernatant } \\
400 \mathrm{~nm} \text { filtrate } \\
\text { Pooled gradient peak }\end{array}$ & $\begin{array}{l}7 \cdot 9 \\
7 \cdot 8 \\
3 \cdot 5 \\
0 \cdot 6\end{array}$ & $\begin{array}{r}100 \\
99 \\
44 \\
7.6\end{array}$ & $\begin{array}{l}0.35 \\
0.28 \\
0 \cdot 14 \\
0.02\end{array}$ & $\begin{array}{r}100 \\
80 \\
40 \\
6\end{array}$ & $\begin{array}{l}0.04 \\
0.04 \\
0.04 \\
0.03\end{array}$ \\
\hline 2 & $\begin{array}{l}\text { Homogenate, unlabelled } \\
200 \mathrm{~g} \text { supernatant } \\
400 \mathrm{~nm} \text { filtrate } \\
\text { Pooled gradient peak }\end{array}$ & $\begin{array}{l}22 \\
21 \\
12 \\
6 \cdot 4\end{array}$ & $\begin{array}{r}100 \\
96 \\
55 \\
29\end{array}$ & $\begin{array}{c}- \\
-\end{array}$ & - & - \\
\hline
\end{tabular}

significantly larger than the EBs, we attempted to remove them by filtering through membrane filters, pore size $400 \mathrm{~nm}$. Cellulose acetate, cellulose nitrate and fluorocarbon filters were found to be unsuitable since more than $80 \%$ infectivity was lost, presumably due to adsorption of EBs to these materials. Polycarbonate filters yielded filtrates containing most of the infectivity, and when such filtrates were subjected to velocity sedimentation through $10-40 \%(w / v)$ sucrose gradients, pure EBs, uncontaminated with non-EB material (Figs $2 a$ 

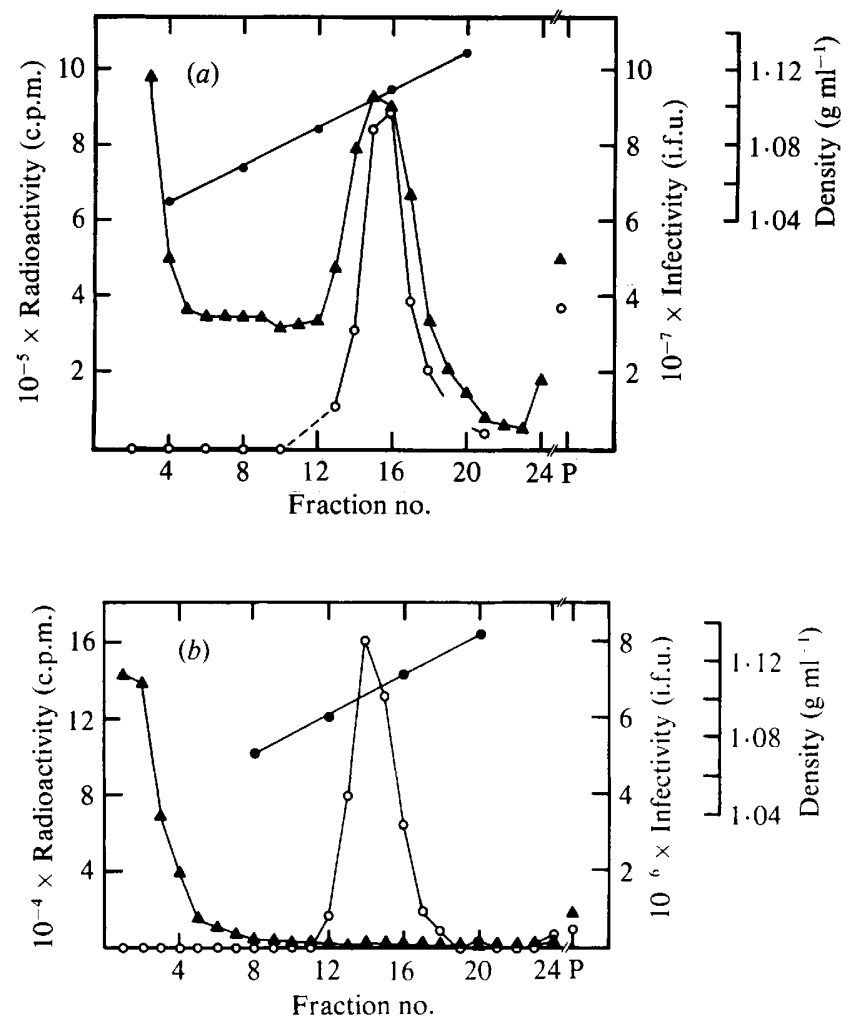

Fig. 2. (a) Purification of infectious elementary bodies of $C$. trachomatis LGV 434 by velocity sedimentation in $10-40 \%(w / v)$ sucrose. Labelling of a chlamydia-infected HeLa 229 culture in a Falcon $175 \mathrm{~cm}^{2}$ flask was with $\left.{ }^{35} \mathrm{~S}\right]$ methionine $\left(25 \mu \mathrm{Ci} \mathrm{ml}^{-1}\right)$ and the sample had been filtered through a polycarbonate membrane filter. Other details are stated in Methods. (b) Unlabelled chlamydia-infected (46 h after infection) HeLa cells were mixed with uninfected cells labelled with ${ }^{3} \mathrm{H}$-labelled amino acids mixture $\left(25 \mu \mathrm{Ci} \mathrm{ml} \mathrm{m}^{-1}\right)$. The mixture was homogenized and subjected to the purification procedure described in Methods. Radioactivity per fraction ( $\boldsymbol{\Delta})$, infectivity per fraction (O) and density (O) were determined. (P denotes pellet.)

and 3), or with host proteins (Fig. $2 b$ ) were obtained. The yield of infectious LGV 434 in the peak fractions of sucrose gradients ranged from 5 to $30 \%$ of that in the initial cell homogenate (Table 1). Similar results were obtained with LGV 404. It should be noted that in expt 1, Table 1, the specific activity, i.e. radioactivity per i.f.u., remained almost constant, despite the decrease in yield, suggesting that lysis (rather than inactivation only) of the EBs was responsible for the resultant yield. Velocity sedimentation through Renografin gradients presented no advantage over sucrose gradients. With the labelling conditions used, little trichloroacetic acid-soluble radioactivity was detected after the sedimentation of the pooled peak fractions.

We examined the samples of purified EBs at low magnification so that the homogeneity of these preparations could be documented without any bias in selecting the fields.

A single freeze-thaw cycle at any stage resulted in a loss of infectivity of at least one order of magnitude: indeed, the surviving EBs were so damaged that continuous loss of infectivity of $C$. trachomatis LGV 434 and 404 occurred throughout the purification process. Therefore, only freshly harvested infected cells were used for obtaining pure EBs.

The association of purified EBs of LGV 434 and 404 with confluent cultures of HeLa cells was linear with time of incubation at $37^{\circ} \mathrm{C}$ for $30-60 \mathrm{~min}$, after which the rate of association 


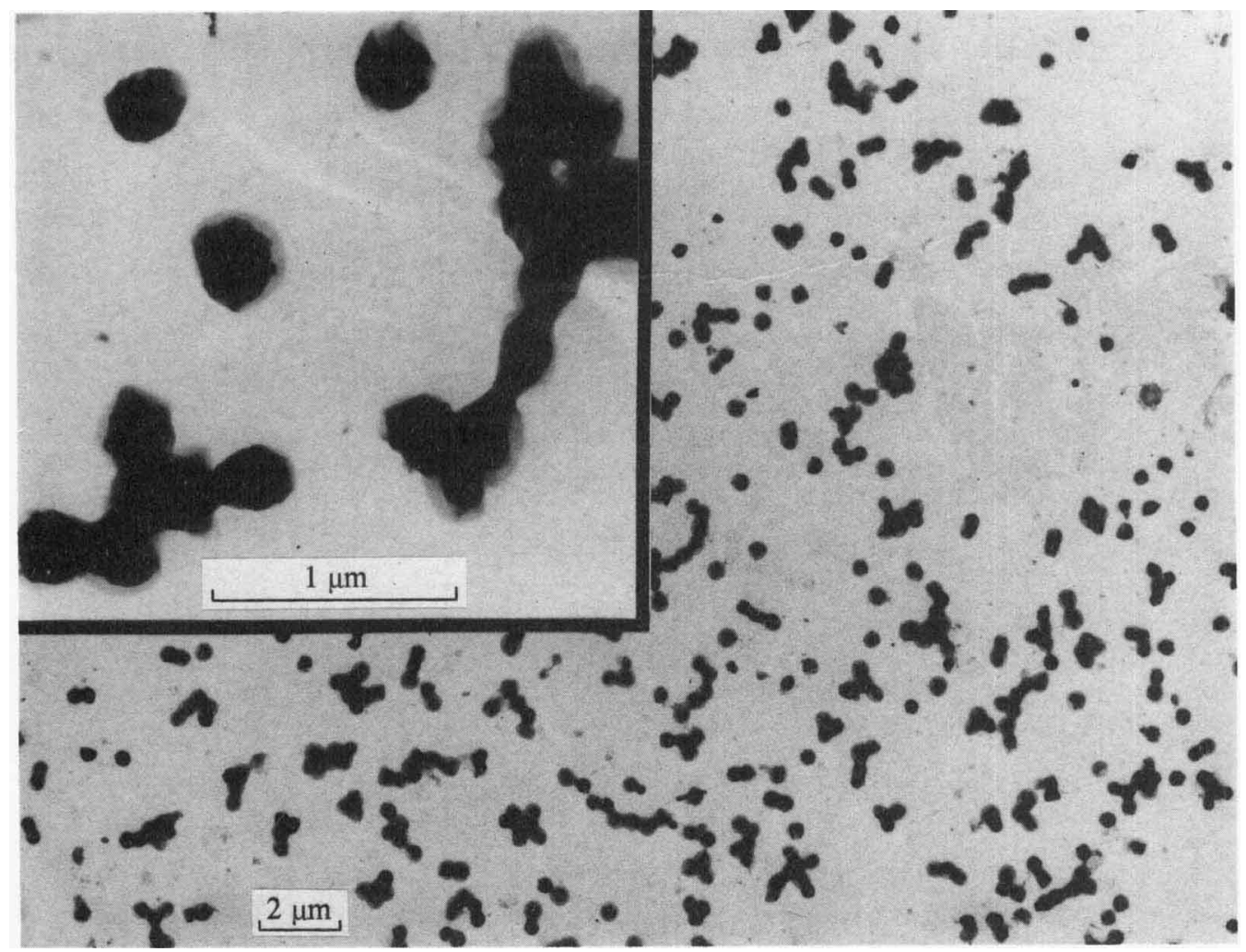

Fig. 3. Electron micrograph of purified elementary bodies of C. trachomatis LGV 434 (fraction 16 of Fig. $2 a$ ). Note the absence of non-elementary body material (cf. Fig. 1). The inset shows the electron-dense coccoid EBs at higher magnification.

decreased (data not shown). A 30-45 min incubation was chosen for all subsequent studies of LGV $434-\mathrm{HeLa}$ cell interaction, about $10 \%$ of the input radioactivity having become associated by this time. A linear relationship existed between the rate of association and the chlamydial inoculum when the chlamydial i.f.u. to HeLa cell ratio was varied from 1 to 100.

\section{Effect of host cell modifications on the rate of association of purified EBs and on the biological activity of purified $E B$ S}

Pretreatment of HeLa monolayer cultures for up to $2 \mathrm{~h}$ with DEAE-dextran ( $75 \mu \mathrm{g} \mathrm{ml}^{-1}$ ), wheat germ agglutinin, concanavalin $\mathrm{A}$ and Dolichos biflorus, Glycine max and Tetragonolobus purpureas lectins $\left(25-100 \mu \mathrm{g} \mathrm{ml}^{-1}\right)$, and neuraminidases $(\mathrm{Cl}$. perfringens and $V$. cholerae) had no effect on the subsequent association and development of inclusions using purified EBs or crude homogenates of C. trachomatis LGV 434 (Table 2). The association of purified EBs of LGV 404 to HeLa cells was also insensitive to these lectins. Dextran sulphate, present only during the adsorption of EBs to HeLa cells, inhibited both the association and inclusion formation of purified EB (Table 2), confirming the observations of Kuo et al. (1973). Pretreatment of HeLa cultures with trypsin reduced their capacity to bind purified EBs of LGV 434. In this respect the interaction of C. trachomatis LGV 434 and 404 resembled that of $C$. psittaci $6 \mathrm{BC}$ and $C$. trachomatis LGV 440L with HeLa 229 and L cells (Byrne \& Moulder, 1978), but differed from that of trachoma G17 (Lee, 1981). 
Table 2. Effect of treatment of HeLa 229 cultures with different reagents on the association of purified $E B S$

HeLa cultures were treated at $37^{\circ} \mathrm{C}$ as follows: DEAE-dextran (mol. wt $2 \times 10^{6}$ ) and $V$. cholerae neuraminidase, $120 \mathrm{~min}$ before infection; $\mathrm{Cl}$. perfringens neuraminidase and the lectins, $60 \mathrm{~min}$ before infection; dextran sulphate and $\mathrm{N}$-acetylneuraminic acid, at the time of infection; trypsin (DPCCtreated), $15 \mathrm{~min}$ before infection followed by soybean trypsin inhibitor immediately prior to infection. Suitable controls were included and the results are averages ( \pm s.E.) of six independent experiments using preparations of purified LGV 434 EBs labelled with $\left[{ }^{35} \mathrm{~S}\right]$ methionine, ${ }^{3} \mathrm{H}$-labelled amino acids or ${ }^{32} \mathrm{P}$.

Reagent

DEAE-dextran

Dextran sulphate

$N$-Acetylneuraminic acid

$C l$. perfringens neuraminidase

$V$. cholerae neuraminidase

Lectins:

Concanavalin A

Dolichos biflorus

Glycine max

Tetragonolobus purpureas

Wheat germ agglutinin

Trypsin
Concn

$75 \mu \mathrm{g} \mathrm{ml}^{-1}$

$5 \mu \mathrm{g} \mathrm{ml}^{-1}$

$5 \mathrm{mg} \mathrm{ml}^{-1}$

0.5 unit $\mathrm{ml}^{-1}$

50 units $\mathrm{ml}^{-1}$

$25-100 \mu \mathrm{g} \mathrm{ml}^{-1}$

$\begin{array}{rl}108 & \pm 7 \cdot 4 \\ 97 & \pm 15 \cdot 0 \\ 117 & \pm 8 \cdot 0 \\ & 70 \pm 2 \cdot 4 \\ 89 & \pm 15 \cdot 0 \\ 25 \mu \mathrm{g} \mathrm{ml}^{-1} & 48 \pm 1 \cdot 5\end{array}$

\author{
Association \\ (\% of control) \\ $112 \pm 4.5$ \\ $34+1.0$ \\ $100 \pm 7 \cdot 5$ \\ $113 \pm 3 \cdot 5$ \\ $101 \pm 11 \cdot 0$ \\ $108+7.4$ \\ $97 \pm 15.0$ \\ $70+2.4$ \\ $89 \pm 15.0$
}

Effect of chlamydial modifications on the association of purified EBs with HeLa 229 cells

The ability of gradient-purified EBs of C. trachomatis LGV 434 to associate with and develop inclusions in HeLa 229 cultures was not affected by the following treatments: DPCC-treated trypsin or chymotrypsin (each at $50 \mu \mathrm{g} \mathrm{ml}^{-1}$ ), V. cholerae neuraminidase (50 units per $2.8 \times 10^{5}$ i.f.u.), $C l$. perfringens neuraminidase $\left(0.5\right.$ units per $9.5 \times 10^{5}$ i.f.u. $)$, and DEAE-dextran $\left(75 \mu \mathrm{g} \mathrm{ml}^{-1}\right)$. The following carbohydrates were found to be ineffective in reducing the association to HeLa cells of purified, labelled LGV 434 EBs: sialic acid ( $5 \mathrm{mg} \mathrm{ml}^{-1}$ ), fetuin $\left(5 \mathrm{mg} \mathrm{ml}^{-1}\right)$, D-mannose, methyl-D-mannoside, D-mannitol, D-fructose, $N$-acetyl-D-glucosamine, $N$-acetyl-D-galactosamine and D-galactosamine (all at $25 \mathrm{mg} \mathrm{ml}^{-1}$ ). Heating the purified $\mathrm{EBs}$ at $56^{\circ} \mathrm{C}$ or $60^{\circ} \mathrm{C}$ for 30 or $3 \mathrm{~min}$, respectively, completely destroyed chlamydial inclusion-forming activity and partially inhibited the rate of uptake of labelled pure EBs of LGV 434 and 404.

\section{DIS C US SION}

Sedimentation to equilibrium in Renografin or in sucrose gradients yielded preparations of EBs of C. trachomatis LGV 434 and 404 which, while free of host proteins, invariably contained the larger RBs. A similar conclusion was reached with yolk sac-grown $C$. trachomatis banded to equilibrium in Renografin gradients where the peak of infectious material contained both forms of the chlamydiae (Howard et al., 1974). In a number of studies velocity sedimentation through sucrose gradients has been used to obtain nearly homogeneous preparations of EBs of C. psittaci (Costerton et al., 1975; Stephenson \& Storz, 1975) and C. trachomatis T'ang strain (Sarov \& Becker, 1968). Treatment with trypsin, RNAase, DNAase and sonication of samples prior to zone sedimentation through sucrose gradients was employed to destroy the non-EB material selectively in the $C$. psittaci preparations (Stephenson \& Storz, 1975; Tamura \& Higashi, 1967). However, in our hands, infectivity of C. trachomatis LGV 434 was rapidly lost by sonication (Branson Sonifier, model LS-75). Only velocity sedimentation of filtered samples yielded preparations of EBs which were free of the larger RBs as revealed by electron microscopic examination (Fig. 3), 
and of host cell-derived polypeptides as measured by a sensitive radioactive method (Fig. $2 b$ ). The achievement of constant specific activity (Table 1) during purification of radioactively labelled samples indicates that homogeneous preparations of EBs of C. trachomatis LGV 434 have been obtained by the procedure developed. Other than mild trypsin treatment to detach infected cells, no chemical or enzymic treatment was introduced, to avoid modification of the EBs. Only freshly purified preparations were used to study various aspects of EB-HeLa cell interactions.

The unusually efficient 'parasite-specified' (Byrne \& Moulder, 1978) mode of association observed for $C$. psittaci $6 \mathrm{BC}$ and $C$. trachomatis LGV strain 440L with L and HeLa cells is also manifested by the highly purified EBs of LGV 434 and 404 in that 10-20 times as many of the input labelled chlamydiae become firmly associated with the 'non-professional phagocytic' HeLa 229 cultures compared with Escherichia coli or Staphylococcus aureus (data not shown). In terms of requirements for association of LGV 434 or 404 with HeLa 229 cells, however, several differences exist, distinguishing these serotypes from LGV strain 440L and C. psittaci 6BC. The most clear-cut difference is the lack of inhibition of association by treatment of the host or of the EB with a variety of lectins, including wheat germ agglutinin (Table 2), a lectin which inhibits the attachment of $C$. psittaci $6 \mathrm{BC}$ and LGV strain 440L to L, McCoy, Vero, HeLa and Hep-2 cells (Levy, 1979). Even though neuraminidase treatment of HeLa cells did not inhibit the development of inclusions after infection with three different LGV serotypes, ovomucoid- and $N$-acetylneuraminic acidpretreated HeLa cultures became resistant to infection with LGV 434 (Kuo et al., 1973). The insensitivity to the five lectins reported in this study (Table 2) suggests that either the HeLa receptors for the association of LGV 434 were inaccessible to the lectins or the specific sugar residues ( $\mathrm{N}$-acetylglucosamine, $\mathrm{N}$-acetylgalactosamine, mannose, galactose and fucose) were not involved in the HeLa cell-LGV 434 and 404 association. The complementary results, i.e. the inability of a variety of sugars to affect the association kinetics, confirm that, unlike the LGV strain 440L (serotype 1) studied by Levy (1979), not only is the association of LGV 434 (serotype 2) and LGV 404 (serotype 3) with HeLa cells completely insensitive to wheat germ agglutinin treatment of the host cells, but also that these two serotypes may associate with HeLa cells via receptors which are not affected by the five lectins tested.

Of the agents tested, heat-inactivation of chlamydiae, and trypsin and dextran sulphate treatment of $\mathrm{HeLa}$ cultures were the only ones producing significant reduction in the association of EBs of LGV 434 and 404 with HeLa 229 cultures, confirming the observations of Kuo et al. (1973) and Kuo \& Grayston (1976). It is noteworthy that the non-LGV G17 strain of $C$. trachomatis has shown association to host cells which is insensitive to mild heating of the chlamydiae, and additionally, trypsin-treated HeLa cells were unaffected in their ability to ingest and form inclusions after infection with this strain (Lee, 1981). The LGV 434 and 404 strains used in the study reported here seem to share some, but not all, properties of LGV 440L, of C. psittaci and of C. trachomatis G17 strain, indicating again (Lee, 1981) that chlamydial strains, at least the laboratory-adapted ones, may have acquired different ligands to associate with host cells cultured in vitro.

This study was supported by a grant from the National Institutes of Health (AI-16577-02). We express our appreciation to Ms Kristi Scaparro and Mr R. L. Mudd for expert technical assistance, and to Ms Robin Fark and Mrs Sharon Hanlon for their secretarial assistance.

\section{REFERENCES}

Bollum, F. J. (1966). Filter paper disk techniques for assaying radioactive macromolecules. In Procedures in Nucleic Acid Research, pp. 296-306. Edited by G. L. Cantoni \& D. R. Davies. New York: Harper \& Row.
Bose, S. K. \& Liebhaber, H. (1979). Deoxyribonucleic acid synthesis, cell cycle progression, and division of Chlamydia-infected HeLa 229 cells. Infection and Immunity 24, 953-957. 
BYRNE, G. I. (1978). Kinetics of phagocytosis of Chlamydia psittaci by mouse fibroblasts ( $\mathrm{L}$ cells): separation of the attachment and ingestion stages. Infection and Immunity 19, 607-612.

Byrne, G. I. \& Moulder, J. W. (1978). Parasitespecified phagocytosis of Chlamydia psittaci and Chlamydia trachomatis by $\mathrm{L}$ and HeLa cells. Infection and Immunity 19, 598-606.

ChEN, T. R. (1977). In situ detection of mycoplasma contamination in cell cultures by fluorescent Hoechst 33258 stain. Experimental Cell Research 104, 255-262.

Costerton, J. W., Poffenroth, L., Wilt, J. C. \& Kordova, N. (1975). The effect of purification on the ultrastructure and infectivity of egg-attenuated Chlamydia psittaci (6BC). Canadian Journal of Microbiology 21, 1448-1463.

Fris, R. R. (1972). Interaction of $L$ cells and Chlamydia psittaci: entry of the parasite and host response to its development. Journal of Bacteriology 110, 706-721.

Furness, G., Graham, D. M. \& Reeve, P. (1960). The titration of trachoma and inclusion blennorrhoea viruses in cell cultures. Journal of General Microbiology 23, 613-619.

Howard, L., OREnstein, N. S. \& KING, N. W. (1974). Purification on Renografin density gradients of Chlamydia trachomatis grown in the yolk sac of eggs. Applied Microbiology 27, 102-106.

Kuo, C.-C. \& Grayston, J. T. (1976). Interaction of Chlamydia trachomatis organisms and HeLa 229 cells. Infection and Immunity 13, 1103-1 109.
Kuo, C.-C., WanG, S.-P. \& Grayston, J. T. (1973). Effect of polycations, polyanions, and neuraminidase on the infectivity of trachoma-inclusion conjunctivitis and lymphogranuloma venereum organisms in HeLa cells: sialic acid residues as possible receptors for trachoma-inclusion conjunctivitis. Infection and Immunity $\mathbf{8}$, 74-79.

LEE, C. K. (1981). Interaction between a trachoma strain Chlamydia trachomatis and mouse fibroblasts (McCoy cells) in the absence of centrifugation. Infection and Immunity 31, 584-591.

LEVY, N. J. (1979). Wheat germ agglutinin blockage of chlamydial attachment sites: antagonism by $N$ acetyl-D-glucosamine. Infection and Immunity 25, 946-953.

Sarov, I. \& Becker, Y. (1968). RNA in the elementary bodies of trachoma agent. Nature, London 217, 849-852.

Stephenson, E. H. \& Storz, J. (1975). Protein profiles of dense-centered forms of five chlamydial strains of animal origin. American Journal of Veterinary Research 36, 881-887.

Tamura, A. \& Higashi, N. (1967). Purification and chemical composition of meningopneumonitis virus. Virology 20, 596-604.

Wise, K. S., Cassell, G. H. \& Acton, R. T. (1978). Selective association of murine $\mathrm{T}$ lymphoblast cell surface alloantigens with Mycoplasma hyorhinis. Proceedings of the National Academy of Sciences of the United States of America 75, 4479-4483. 